\title{
The Effect of Family-Based Empowerment on Adolescent's Nutritional Statusin Tana Toraja
}

\author{
Erni Yetti R. ${ }^{1}$, Zadrak Tombeg ${ }^{2}$, Anto J. Hadi ${ }^{3}$, Saskiyanto Manggabarani ${ }^{4}$ \\ ${ }^{1}$ Lecturer of Health Promotion and Behavioral Science, Akademi Kebidanan Sinar Kasih Toraja, Tana Toraja, \\ Indonesia, ${ }^{2}$ Lecturer of Mother and Children Health, Akademi Kebidanan Sinar Kasih Toraja, Tana Toraja, \\ Indonesia, ${ }^{3}$ Lecturer of Public Health, Fakultas Kesehatan, Universitas Aufa Royhan, Padangsidimpuan, \\ Indonesia, ${ }^{4}$ Lecturer of Nutrition, Sekolah Tinggi Ilmu Kesehatan Pertamedika, Jakarta, Indonesia
}

\begin{abstract}
Adolescent's nutritional status is one of the problems of public health nutrition. Adolescents or teenagers are a group that is sensitive to nutrition which has an impact on increasing the prevalence of degenerative diseases due to excess nutrition. This study aimed to analyze the effect of family-based empowerment on the teenager's nutrition status in Tana Toraja. The research design used a quasy-experiment with a pre-test and post-test design with a control group design. It was carried out on 64 overweight students consisting of 32 intervention groups and 32 control groups as well as simple random sampling and data analysis using Hotelling's $\mathrm{T}^{2}$ test. The results showed that family-based empowerment was significant in reducing overweight case due to adolescent's nutritionalstatus against obesity prevention with a value of $p=0.000$ $<0.05$. The conclusion of this study is that there is an effect of family-based empowerment on the adolescent's nutritional status in Tana Toraja. It can be a reflection for teenagers who have experienced an overweight nutritional status so they can adopt a healthy diet. This study shall performed further in public nutritional status.
\end{abstract}

Keywords: Nutritional Status; Adolescent; Empowerment; Family.

\section{Introduction}

The increased prevalence of obesity in adolescents is placed as a risk factor for degenerative diseases among youth. Risk factors for obesity include an energy-dense diet, high consumption of sugary drinks, a diet such as snacking and high sedentary behavior level. The case are also worse with the number of low physical activity level intake, especially in daily basis. Research reports show that obesity is associated with a high intake of energy dense, low in foods such as soft drinks, savory

\section{Corresponding Author:}

\section{Erni Yetti R.}

Akademi Kebidanan Sinar kasih Toraja, Tana Toraja, Indonesia

Buntu Pantan 8 Makale Street, Tana Toraja, Sulawesi

Selatan, Indonesia

Office Phone Number: +62 42322585

Personal Phone Number:+62 8124135637

e-mail: erniyetti12345@gmail.com chips, sweet biscuits and sweets, and also an increase in the time spent in their association ${ }^{(1)}$. Based on the 2013 South African National Health Report and Screening Survey (SANHANES-1), the number of participants who aged 18-24 were reported to be inactive and overnourished $(50.2 \%)^{(2)}$.

WHO warns that obesity and overweight cases are the fifth leading risks of global death ${ }^{(3)}$.Cardiometabolic risk factors in obese adolescents in Kuwait have a poor quality of life and health compared to adolescents with healthy weight, this can be seen in cultural differences between western and Kuwait societies ${ }^{(4)}$. The increasing occurrence of obesity has also reported in developing countries such as Indonesia. Basic Health Research or Riset Kesehatan Dasar (Riskesdas) Indonesia in 2013 shows that nationally the prevalence of fat among adolescents aged 13-15 years in Indonesia is $10.8 \%$, consisting of $8.3 \%$ overweight and $2.5 \%$ obesity. The province with the highest prevalence of overweight and obesity was DKI Jakarta (4.2\%) and the lowest was West Sulawesi $(0.6 \%)^{(5)}$. 
South Sulawesi Province is one of 16 provinces whose population experiences less activity above the national prevalence, namely 49.1\% $(<150$ minutes per week) and eating less fruits and vegetables $93.7 \%$ $\left(<5\right.$ servings per day) ${ }^{(6)}$. The same thing happened to Riskesdas (2013), namely the less active activity of the age group $\geq 10$ years by $31 \%$, exceeding the Indonesian average value of $26.1 \%$. Based on Riskesdas (2013) in numbers, the prevalence of overweight in South Sulawesi province according to $\mathrm{BMI} / \mathrm{U}$ age $13-15$ years is $6.8 \%$ fat and $2.4 \%$ obese, and in Tana Toraja Regency as much as $10.5 \%$ fat and $2.3 \%$ obesity ${ }^{(5)}$.

Changes in dietary habits in adolescents, based on previous research, if not attempted to improve it will bring the influence of the quality of society towards. As one of death factor, this research focused on the occurrence of overweight and obesity in adolescent in Indonesia. The recent cases of obesity has a put the problems of obesity in the next generationafterwards. Otherwise, it is necessary to seek information and treatment in a form of interventionregarding adolescent obesity through family-based empowerment models ${ }^{(7)}$. The findings about the incidence of overnutrition are the result of unhealthy eating behavior and less physical activity, therefore it is necessary to improve behavior and increase the physical activity of adolescents so as to reduce prevalence and prevent excess complications and obesity. With empowerment based on family nutrition education, it is used to improve diet so that it can reduce the nutritional status of overweight adolescents to normal. The purpose of this study was to analyze the effect of family-based empowerment on the nutritional status of adolescents in Tana Toraja.

\section{Material and Method}

Research Design: A method to be used in this study was taken to quasy-experiment approach. As the research design, pretest and post-test with control group design was elaborated to determine before and after treatment. The study group in this study was divided into 2 (two) groups consisting of 1 (one) treatment group and 1 (one) control group. The first group was given intervention in a form of health education through family empowerment with modules, the second group (control) was given health education with modules and family mentoring without role playing.
Population and Sample: The population and sample in this study were some of the parents and overweight adolescents in grades 7 and 8 at the Junior High School in Tana Toraja. The sampling technique in this study was simple random sampling method, namely selecting a sample among the population by drawing lots. The samples number was 32 for the treatment group and 32 for the control group. The number of 32 obtained in the calculation of the sample size above is obtained by entering the data on the number of populations, the expected error rate, the range of the level of accuracy/ accuracy and the desired level of confidence into the Sample Size Determination (SSD) in Health Studies.

Data Collecting: The anthropometric assessment of adolescents was carried out using the Camry brand digital scale as a measuring tool for children's body weight with an accuracy of $0.1 \mathrm{~kg}$ and a capacity of $150 \mathrm{~kg}$ and Microtoise as a measuring device for height with an accuracy of $0.1 \mathrm{~cm}$ and a capacity of $200 \mathrm{~cm}$. Then the anthropometric index used was body mass index per age (BMI/A) WHO Antrhoplus software 2007 reference standard for school age children 5-18 years and nutritional behavior was assessed by a questionnaire consisting of 15 question items.

Data Analysis: Analysis we have done was taken into the determination of test significance as well as the determination of the difference in the mean of research variables. The data was collecting between before and after the intervention. If the data distribution was normally distributed, the independent t-test or paired t-test was used based on the group, while the non-normal distribution used the Mann-Whitney non-parametric test and multivariate analysis by using Hoteling's $\mathrm{T}^{2}$ test to see the difference between the two test groups (treatment group and control group). Each of which contains at least two or more variables and will be analyzed simultaneously together.

\section{Results}

Adolescent's Characteristics: The location of this research wasMakale City Junior High School, Tana Toraja Regency, South Sulawesi Province. The data is processed and analyzed according to the research objectives. Data results analysis are presented in tabular form equipped with the following explanation. The distribution of adolescent's nutritional status can be seen in Table 1. 
Table 1. Distribution of Adolescent's Nutritional Status

\begin{tabular}{|l|c|c|c|c|}
\hline \multirow{2}{*}{ Nutritional Status } & \multicolumn{2}{|c|}{ Pretest } & \multicolumn{2}{c|}{ Post-test } \\
\cline { 2 - 5 } & $\mathbf{n}$ & $\mathbf{n}$ & $\mathbf{n}$ \\
\hline Treatment & 32 & 100.0 & 16 & 50.0 \\
\hline Overweight & 0 & 0.0 & 16 & 50.0 \\
\hline Normal & 32 & 100.0 & 21 & 65.6 \\
\hline Control & 0 & 0.0 & 11 & 34.4 \\
\hline Overweight & 32 & \\
\hline Normal &
\end{tabular}

Table 1 shows that all adolescent's nutritional status of research measurement during the pre-test had overweight nutritional status. After the post-test, 16 adolescents $(50 \%)$ had normal nutritional status in the treatment group and 21 adolescents $(65.6 \%)$ had also normal nutritional status. The differences then were analyzed by Mann-Whitney test.

\section{Changes in Adolescent's Nutritional Status:}

Table 2. Changes in Adolescent's Nutritional Status Before and After Intervention or Treatment

\begin{tabular}{|l|c|c|c|c|}
\hline Nutritional Status & Pretest & Post-test & Difference & p \\
\hline Treatment & 24.25 & 23.31 & 0.94 & $0.000^{*}$ \\
\hline Control & 23.95 & 23.43 & 0.52 & $0.000^{*}$ \\
\hline
\end{tabular}

*Mann-Whitney

Table 2 shows that the results of the Mann-Whitney test. It shows that the change in respondents' nutritional status (BMI) were recorded at post-test. The difference was quite significant compared to pre-test. This shows that there is a difference in BMI in the pre-test and post-test in both the treatment and control groups. The decrease in BMI was more significant (higher in number) in the treatment group than in the control group.

Multivariate analysis of differences in the effect of family-based empowerment on adolescent nutritional status can be seen in Table 3 .

\section{Multivariate Analysis Results:}

Table 3. Multivariate Analysis Results on Nutritional Status Difference through Family-Based Empowerment

\begin{tabular}{|l|c|c|c|}
\hline Family-Based Empowerment & Value & F & Sig \\
\hline Hotelling's Trace Analysis Results of Nutritional Status & 0.721 & 8.472 & $0.000^{*}$ \\
\hline
\end{tabular}

*Hotelling's T

Table 3 shows that the results of statistical tests with Hoteling's $\mathrm{T}$ test. It was obtained that the value of $\mathrm{F}=$ 8.472 and $p=0.000(p<0.05)$. This means that there are differences in the nutritional status of adolescents who receive family-based empowerment. Family-based empowerment affected nutritional status of adolescents as family members $(p<0.05)$.

\section{Discussion}

In line with the existence of a high-calorie diet, the low frequency of physical activity and lots of free time activities have contributed to an increase in the prevalence of overweight and obesity among adolescents as the research objective in this study. The results showed that the results of the Mann Whitney 
test showed that there was a change in nutritional status during the post-test compared to the pretest. This shows that there is a difference in body mass index (BMI) in the pretest and post-test in both the treatment and control groups. The decrease in body mass index (BMI) was higher in the treatment group than in the control group. For counterfeit analysis, the research of Tuah et al. (2011) that the use of the Stage of Change (SOC) on Transtheorical Model (TTM) in maintaining the obesity weight management programs supported our findings. The supported sidewas taken as if the SOC was effective for weight loss in adolescents ${ }^{(8)}$.Johnson et al. (2008) has conducted the research related to adult obesity. The research focused on respondents with BMI ranged from 25-39.9. The number of respondents in the research were 1277.Under multiple behavior interventions, this study shows the patterns on results due to ability of TTM. TTM tend to be effective in improving healthy eating patterns, holding exercise schedule of respondents, managing emotional distress, changing behavior and maintaining body weight ${ }^{(9)}$. Multiple behavior interventions have been proven to elaborate the impact in this research. In this study, we found that the results were three times better than single behavior interventions. Health promotion in the proper community agenda or obesity prevention programs held by formal health practitioners together with the government and/or mentors are quite effective. The results from previous study found that health promotionwas able to prevent an increase in BMI. IN addition, it can also lead to reducing snacks intake by respondents, cutting soft drinksconsumption off or limiting respondents from eating desserts after meal course so that the improvement can be achieved ${ }^{(10)}$.

Multicomponent intervention, according to Foster, is also significant to uphold. The method whatsoever is proven to prevent the development of obesity cases, especially in children in grades 4-6 located in urban elementary schools ${ }^{(11)}$. Based on need-based analysis, community-based partnershipshave been provoking to integrate health, education, environment, government and business services altogether. Golan \& Weizman (2001) developed the research model in the form of family-based conceptual model. It emphasizes two main points, namely healthy lifestyle and weight loss (12). According to Watson in Potter (2005) to improve health is to return the client to his healthy condition and prevent pain $\left.{ }^{(13}\right)$. Furthermore, parental caring behavior will bring the influence as if it is very important in preventing the effect of the certain diseases on children and in this studychildren who are overweigth and obese are being the main focus. A program to hold and uprise African American students' awareness on obesity and overweight cases. It was conducted to preserve the risk of heart disease and diabetes towards ${ }^{(14)}$. Jones et al (2010) revealed the beneficial sides of the health information technology (IT) and health literacy (HL) programs. The effectiveness of the two health promotion methodwas determined to raise awareness about the health risks of obesity among African American students (15).

The regular measurement conducted in this study found various changes in body mass index (BMI) in respondents. Both groups experienced a decrease in BMI at the sixth month based on pretest and post-test measurement. The decrease number of BMI in the treatment group was $90.3 \%$. The result number was higher than the control group that was only getting into $21.2 \%$ of threshold value. Balanced healthy menu based on age was given as one of interventions. The other interventions given were one-hour physical activity on a daily basis andthe maintained children's healthy behavior. The interventions in our study adopted and developed from Barlow (2007). The research done by Barlowhas been recommending children and families to maintain food intake, physical activity and relaxing habits; or in this case is sedentary behavior. Mushtaq et al. (2011) foundtwo of independent predictors of obesity of school-aged children in Pakistan were physical activity and daily lifestyle. Daily lifestyle included watching television, working on computers and playing video games. The three parameters showed a significant association with a high BMI and the risk of being overweight and at risk of health disease with the OR score of 1.60 in children without normal BMI. Based on the nutritional status of adolescents we elaborated in this study, there were reported that overweight adolescents the treatment group tend to have normal nutritional statusafter the intervention. This study proves that family-based empowerment played a huge role as health intervention as it greatly affected adolescent's BMI reduction. It also influenced the changes in better and normal adolescent nutritional status. Due to deep analysis in pilot study comparison, the module content we developed is equipped with information on healthy lifestyles and youth monitoring sheets. It can help families to be the role of culture care repatterning so that they can control the family member's physical activity and food intake afterwards. Families also believe that they are able to carry out a healthy lifestyle in children with good family self-efficacy. 
Changes in BMI in adolescents are motivation for adolescents to change their lifestyle into healthy behaviors. The way and steps they spend per day inlosing weight motivation in adolescents is the key to success as it turns to be motivation to shape the confidence in public appearance. This is because school-age children begin to gain the ability to sequence a number of events and actions, children become physically mature, children became curious and asked a lot about health ${ }^{(16)}$. Thus, the role of the family in controlling the lifestyle of adolescents by doing good physical activity as many as 32 adolescents has an impact on changes in adolescent BMI, which decreased by $31(97.3 \%)$ in the treatment group. This can be happened after the implementation of family-based empowerment.

The decrease in BMI in the treatment group showed an increase in knowledge, attitudes, behavior, family culture, physical activity of adolescents from month to month accompanied by adequate calorie intake of children along with the decrease of sedentary activities. Thus, the family is able to control overweight adolescents which has an impact on decreasing the body mass index (BMI) of adolescents. The change in BMI has an impact on the psychosocial development of adolescents according to Erickson in Wong (2009) that if adolescents cannot resolve conflicts or problems, they will become inferior. A decreased BMI will have a positive impact on adolescents, namely adolescents are more confident with their body size. A decrease in BMI in adolescents is a change in the positive energy balance to a negative energy balance through biochemical changes, physiological changes, and anatomical changes. Positive energy balance is excessive intake and under exercise in overweight adolescents before the intervention. After the application of the family-based empowerment model, there was a change in BMI, namely a decrease in BMI in the treatment group. This decrease in BMI is the result of a process of anatomical changes that can be measured through anthropometry including adolescent nutritional status based on BMI and adolescent age.

Research by Nayak and Bhat (2010) in which multicomponent intervention was given for one month to 269 children, an amount of 13 (4.8\%) were overweight and $7(2.6 \%)$ were obese ${ }^{(17)}$. Sedentary activity after school hours such as watching television for a longer duration on Sundays and weekdays, decreased physical activity, skipping meals, the influence of the media in choosing food, parents offering food as gifts, frequent consumption of fried and junk food, and frequent drinking carbonated drinks is an important factor in influencing the incidence of overweight and obesity ${ }^{(18)}$. There was a significant reduction in the body mass index (BMI) of the intervention group at the end of the fourth week.

\section{Conclusion}

Family-based empowerment has an effect on decreasing body mass index of adolescent family member (BMI) or adolescent's nutritional status. There was a decrease in the BMI of adolescents in the treatment group but there was an increase in the BMI of adolescents in the control group. We need to monitor adolescent's nutritional status and provide counseling to adolescents regarding healthy eating patterns from an early age.

Ethical Clearance: The results of this study found that eating culture in the local area can affect eating patterns due to geographic conditions, thus impacting on food and energy use so that it affects changes in weight of obese teenagers.

Acknowledgement: The authors thank all the Public Health students who helped in the collection of the data. Tana Toraja Regency Government, Health Service, Head of Community Health Center who has granted research permit. Respondents who have been willing to spend time in the interview process.

Research Funding: Funds used during this research came from private funds.

Conflict of Interest: The author(s) declare that they have no conflict of interest.

\section{References}

1. Leech RM, McNaughton SA, Timperio A. The clustering of diet, physical activity and sedentary behavior in children and adolescents: a review. Int J Behav Nutr Phys Act. 2014;11(1):4.

2. Sedibe HM, Kahn K, Edin K, Gitau T, Ivarsson A, Norris SA. Qualitative study exploring healthy eating practices and physical activity among adolescent girls in rural South Africa. BMC Pediatr. 2014;14(1):211.

3. Go R-E, Hwang K-A, Kim S-H, Lee M-Y, Kim C-W, Jeon S-Y, et al. Effects of anti-obesity drugs, phentermine and mahuang, on the behavioral patterns in Sprague-Dawley rat model. Lab Anim Res. 2014;30(2):73-8. 
4. Boodai SA, McColl JH, Reilly JJ. National Adolescent Treatment Trial for Obesity in Kuwait (NATTO): project design and results of a randomised controlled trial of a good practice approach to treatment of adolescent obesity in Kuwait. Trials. 2014;15(1):234.

5. RI KK. Badan penelitian dan pengembangan kesehatan. Ris Kesehat Dasar. 2018;

6. Dasar RK. Laporan nasional 2007. Badan Penelit dan Pengemb Kesehat Dep Kesehatan, Republik Indones Jakarta Depkes. 2007;

7. Davison KK, Lawson HA, Coatsworth JD. The family-centered action model of intervention layout and implementation (FAMILI) the example of childhood obesity. Health Promot Pract. 2012;13(4):454-61.

8. Tuah NAA, Amiel C, Qureshi S, Car J, Kaur B, Majeed A. Transtheoretical model for dietary and physical exercise modification in weight loss management for overweight and obese adults. Cochrane Database Syst Rev. 2011;(10).

9. Johnson SS, Paiva AL, Cummins CO, Johnson JL, Dyment SJ, Wright JA, et al. Transtheoretical model-based multiple behavior intervention for weight management: effectiveness on a population basis. Prev Med (Baltim). 2008;46(3):238-46.

10. Black RE, Cousens S, Johnson HL, Lawn JE, Rudan I, Bassani DG, et al. Global, regional, and national causes of child mortality in 2008: a systematic analysis. Lancet. 2010;375(9730):1969-87.
11. Foster GD, Sherman S, Borradaile KE, Grundy KM, Vander Veur SS, Nachmani J, et al. A policybased school intervention to prevent overweight and obesity. Pediatrics. 2008;121(4):e794-802.

12. Golan M, Weizman A. Familial approach to the treatment of childhood obesity: conceptual model. J Nutr Educ Behav. 2001;33(2):102-7.

13. Potter PA, Perry AG. Buku ajar fundamental keperawatan: konsep, proses, dan praktik. Jakarta Egc. 2005;1.

14. Williamson W, Kautz DD. Increasing awareness in African American BSN students of the health risks of obesity. ABNF J. 2013;24(2).

15. Jones JM. Nurses top honesty and ethics list for 11th year. Gall Econ. 2010;1-2.

16. Wong DL, Hess CS, Kasprisin CA, Whaley LF. Wong and Whaley's clinical manual of pediatric nursing. Mosby Inc; 1999.

17. Nayak BS, Bhat H V. A study to evaluate the effectiveness of multicomponent intervention on lifestyle practices, body fat and self esteem of obese/ overweight school children in selected English medium schools of Udupi district, Karnataka. Int J Nurs Educ. 2010;2(2):9-12.

18. Hadi AJ, Hadju V, Indriasari R, Sudargo $T$, Nyorong M. Model of Peer intervention Assessment of Nutritional Educator in the Efforts to Change Behaviour in Decreasing Overweight in integrated islamic Elementary Schools at Makassar. Indian J Public Heal Res Dev. 2019;10(9):613-8. 